\title{
A comparison of glycemic parameters and their relationship with C-peptide and Proinsulin levels during partial remission and non-remission periods in children with type 1 diabetes mellitus - a cross-sectional study
}

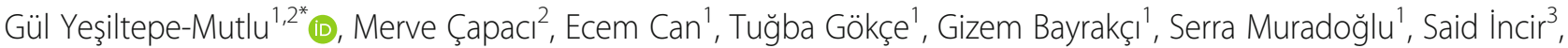
Esra Papatya Çakır ${ }^{4}$ and Şükrü Hatun ${ }^{1,2}$

\begin{abstract}
Background: Currently, there is a lack of data relating to glycemic parameters and their relationship with C-peptide (CP) and proinsulin (PI) during the partial remission period (PRP) in type 1 diabetes mellitus (T1D). The aim of this study was to evaluate glycemic parameters in children with T1D who are in the PRP using intermittently scanned continuous glucose monitoring systems (isCGMS) and to investigate any relationships between $C P$ and PI levels.

Methods: The study included 21 children who were in the PRP and 31 children who were not. A cross-sectional, non-randomized study was performed. Demographic, clinical data were collected and 2 week- isCGMS data were retrieved.

Results: The Serum CP showed a positive correlation with time-in-range in the PRP (p:0.03), however PI showed no correlations with glycemic parameters in both periods. The Serum CP and PI levels and the PI:CP ratio were significantly higher in the PRP group than in the non-PRP group. In the non-PRP group, the PI level was below 0.1 $\mathrm{pmol} / \mathrm{L}$ (which is the detectable limit) in only 2 of the 17 cases as compared with none in the PRP group. Similarly, only 2 of the 17 children in the non-PRP group had CP levels of less than $0.2 \mathrm{nmol} / \mathrm{L}$, although both had detectable PI levels. Overall time-in-range $(3.9-1.0 \mathrm{mmol} / \mathrm{L})$ was significantly high in the PRP group. In contrast, the mean sensor glucose levels, time spent in hyperglycemia, and coefficient of variation levels (32.2vs 40.5\%) were significantly lower in the PRP group.

(Continued on next page)
\end{abstract}

\footnotetext{
* Correspondence: gulyesiltepe@gmail.com; gmutlu@ku.edu.tr

${ }^{1}$ Department of Pediatric Endocrinology and Diabetes, Koç University

Hospital, Topkapı, Zeytinburnu, 34010 Istanbul, Turkey

${ }^{2}$ Koç University School of Medicine, Istanbul, Turkey

Full list of author information is available at the end of the article
}

C The Author(s). 2021 Open Access This article is licensed under a Creative Commons Attribution 4.0 International License, which permits use, sharing, adaptation, distribution and reproduction in any medium or format, as long as you give appropriate credit to the original author(s) and the source, provide a link to the Creative Commons licence, and indicate if changes were made. The images or other third party material in this article are included in the article's Creative Commons licence, unless indicated otherwise in a credit line to the material. If material is not included in the article's Creative Commons licence and your intended use is not permitted by statutory regulation or exceeds the permitted use, you will need to obtain permission directly from the copyright holder. To view a copy of this licence, visit http://creativecommons.org/licenses/by/4.0/. The Creative Commons Public Domain Dedication waiver (http://creativecommons.org/publicdomain/zero/1.0/) applies to the data made available in this article, unless otherwise stated in a credit line to the data. 
(Continued from previous page)

Conclusions: Although the mean glucose and time in range during the PRP was better than that in the non-PRP group, the glycemic variability during this period was not as low as expected. While the CP levels showed an association with TIR during the PRP, there was no correlation between PI levels and glycemic parameters. Further studies are needed to determine if PI might prove to be a useful parameter in clinical follow-up.

Keywords: Type 1 diabetes, Partial remission, C-peptide, Proinsulin

\section{Background}

The transient recovery period of beta-cell function, after initiation of insulin therapy in patients with newly diagnosed type 1 diabetes mellitus, is referred to as the 'honeymoon' or partial remission phase (PRP). The clinical significance of this period lies in the maintenance of glycemic control characterized by a reduction in insulin requirements. Previous controlled trials on the natural course of beta cell function recovery reported the prevalence of remission as 60\%, [1] with a duration ranging from 1 month to as long as 13 years [2]. To achieve better glycemic control throughout the remission phase, several studies focused on the factors influencing the natural course of remission, such as severity of presentation, age at diagnosis, gender, and effects of autoantibodies. Nevertheless, the glycemic parameters and variability in these parameters during the remission period remain unknown.

PRP is defined as an insulin dose-adjusted hemoglobin A1c (HbA1c) (IDAA1c) of equal to or less than 9, where IDAA1c is equal to the sum of HbAlc (\% and $\mathrm{mmol} /$ mol) and 4 times the insulin dose (units/kg/day) [3]. However, this definition based on insulin doses and HbA1c is not sufficient in terms of glycemic variability, insulin sensitivity, and episodes of hypoglycemia and hyperglycemia. Furthermore, there are no definite cutoff values for $\mathrm{C}$-peptide (CP) and proinsulin (PI) levels for the definition of the PRP in type 1 diabetes (T1D). However, the measurement of the CP levels for the definition of the remission period has been established and is a laborious and expensive process [3]. Additionally, an IDAA1C level of 9 has been shown to correspond to a substantially increased predicted stimulated C-peptide (CP) level of $300 \mathrm{pmol} / \mathrm{l}$ [3].

Normal insulin biosynthesis is a multi-step process, beginning with a pre-prohormone, pre-pro-insulin, which is then converted to proinsulin (PI). PI becomes incorporated into a new "immature" beta-granule, where it is subsequently cleaved into insulin and $\mathrm{CP}$ via prohormone convertases (PCSK1, PCSK2, and carboxypeptidase E) [4]. It has been shown that the PI to $\mathrm{CP}$ ratio (PI: CP) increases in individuals at risk of diabetes and at the time of diagnosis of diabetes. On the other hand, Watkins et al. examined PI levels at the time of T1D diagnosis, shortly after diagnosis, and during the PRP and found that the PI level was higher during the PRP than that at the time of diagnosis [5]. However, the importance of neither CP nor PI levels in clinical practice and their effects on glycemic parameters have not been investigated in detail.

In the past, only the HbA1C level was taken into account for defining glycemic control in diabetes. However, new glycemic parameters have emerged in the light of recent advances in diabetes technology. Currently, the definition of RP is still based only on HbA1C levels and insulin doses and there are few studies evaluating other glycemic parameters in this period. In the light of recent technological developments, this study aimed to evaluate the glycemic parameters in children with T1D who are in PRP and compare them with those who are not in this phase using intermittently scanned continuous glucose monitoring systems (isCGMS). The study also aimed to investigate the relationships between PI and CP levels and glycemic parameters in order to draw comparisons between the PRP and non-PRP periods.

\section{Methods \\ Subjects}

The study was conducted between March 2018 and 2019 and included 21 children with T1D who were in PRP (the PRP group) and 31 children with T1D who had been diagnosed at least 2 years before the enrollment and who were not in RP (the non-PRP group). The inclusion criteria required an age of 5 to 18 years and being under multipledose insulin injection therapy and isCGMS. The exclusion criteria were the presence of concomitant diseases that could influence metabolic control, the use of an insulin infusion pump and having HbA1C level above 9\% (75 $\mathrm{mmol} / \mathrm{mol}$ ) (A consort flow diagram is showed in Fig. 1).

\section{Study design}

A cross-sectional, non-randomized study was performed. The study protocol was approved by the Koç University Committee on Human Research (reference number: 2018.022.IRB1.004). Written consent was obtained from the parents along with assent from the adolescents as required by the local institutional review board regulations.

A partial remission phase was defined as an insulin dose adjusted HbA1c (IDAA1c) of equal to or less than 9 [1]. Demographic, socioeconomic, and clinical data were collected from medical records and from interviews with the participants and parents. Also, 2 weeks' isCGMS data were 


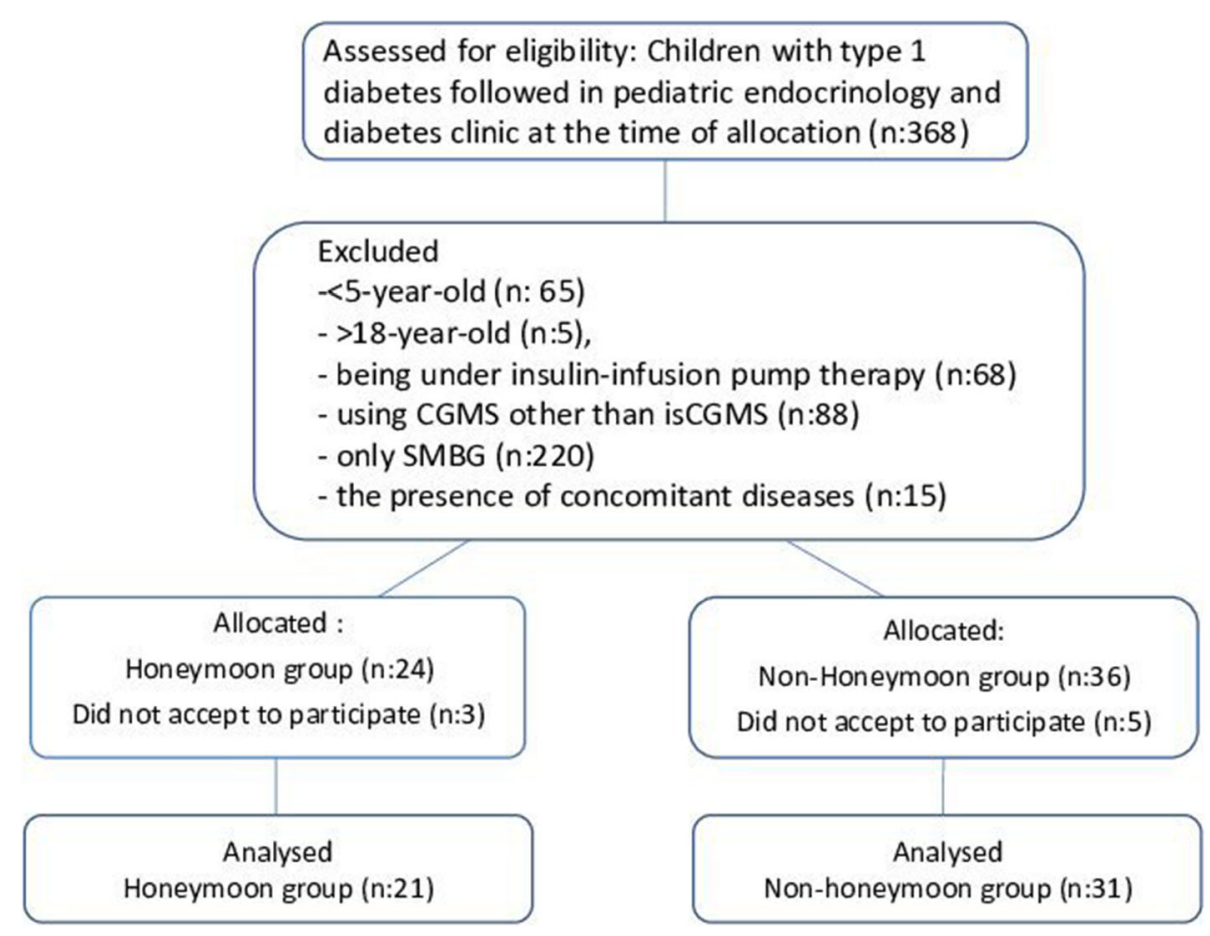

Fig. 1 Study flow diagram

retrieved using the Free-Style Libre software in the outpatient pediatric endocrinology clinic. In addition to the software report, the raw data were used for statistical analysis and assessed according to continuous glucose monitoring systems (CGMS) consensus report [6]. Random (mostly non-fasting) serum samples were collected for measurement of $\mathrm{CP}$ and PI during the routine follow-up visits.

\section{Laboratory analyses}

For the measurement of $\mathrm{CP}$ and PI, samples were collected into dry tubes and centrifuged promptly ( $3500 \mathrm{~g}$ ) for $10 \mathrm{~min}$ at $+4^{\circ} \mathrm{C}$. The sera were separated in aliquots and frozen immediately at $-80^{\circ} \mathrm{C}$. Serum CP and PI levels were determined by competitive ELISA using commercial kits (DRG Instruments $\mathrm{GmBH}$, Germany). Intra- and inter-CVs were 6.54 and $9.33 \%$ for $\mathrm{CP}$, and 4.3 and $6.8 \%$ for PI, respectively. The detection limit was $0.1 \mathrm{pmol} / \mathrm{L}$ for PI [7]. HbA1c levels were analyzed immediately after collecting blood samples into $\mathrm{K}_{2}$-EDTA-added tubes on an ADAMS A1c Lite HA-8380 V analyzer (Arkray) using the HPLC (Reversed-phase cation-exchange liquid chromatography) method. Sustained levels of CP were considered to be consistent readings greater than $0.2 \mathrm{nmol} / \mathrm{l}$ [8].

\section{Statistical analyses}

The sample size calculation was made using OpenEpi Statistical Software version 3.01 [9]. Type 1 error of the study is $\alpha=0,05$, the power of the study is $1-\beta=0,80$, and the number of samples was calculated as 18 per group. A total of at least 40 people had to be included in the study, 20 per group, with an appendix of approximately $10 \%$ loss. The other statistical analyses were conducted using SPSS statistical software version 22 (USA). Descriptive statistics included means, standard deviation (SD), median, interquartile range, and proportions when appropriate. Correlations between CP, PI and glycemic parameters were computed using Spearman's correlation coefficient. For continuous variables, mean \pm standard deviation and median values were used for variables with and without normal distribution, respectively. For continuous variables, the Student's t-test was used for normally distributed data and the Mann-Whitney U-test was used for data without normal distribution.

\section{Results}

The two groups were similar in terms of age and gender. As expected, the mean diabetes duration, daily insulin dose, HbA1c, IDDA1c, estimated HbA1c levels were significantly lower in the PRP group compared with the non-PRP group. However, the serum CP and PI levels and the PI:CP ratio were significantly higher in the PRP group than those in the non-PRP group. The demographic characteristics and laboratory findings of the two groups are given in Table 1. A total of 17 children in each group agreed to give serum samples for the measurement of PI and CP. In the non-PRP group, PI level was below $0.1 \mathrm{pmol} / \mathrm{L}$ (which is the detectable 
limit) in only 2 of the 17 cases as compared with none in the PRP group. Similarly, only 2 of the 17 children in the non-PRP group had CP levels of less than $0.2 \mathrm{nmol} /$ L, although both had detectable PI levels.

When the glycemic parameters were compared in the two groups (Table 2), overall time-in-range, day-time and night-time levels were significantly higher in the PRP group. In contrast, the mean sensor glucose levels (overall, day-time and night-time), the mean time spent in level 1 and level 2 hyperglycemia overall, day-time and night-time, the median time spent in level 1 hypoglycemia $(<3.9 \mathrm{mmol} / \mathrm{L})$ day-time, and the mean coefficient of variation $(\mathrm{CV})$ and SD levels were all significantly lower in the PRP group.

However, the median time spent in level 1 hypoglycemia $(<3.9 \mathrm{mmol} / \mathrm{L})$ overall and night-time were similar in the two groups.

In correlation analyses (Table 3 ), the serum $\mathrm{CP}$ showed a positive correlation with time-in-range (3. 9-10 $\mathrm{mmol} / \mathrm{L}$ ) in the PRP group (Fig. 2), along with inverse correlations with the mean sensor glucose, mean sensor glucose SD and the median time spent in level 1 hyperglycemia. In the non-PRP group, serum $\mathrm{CP}$ was positively correlated with the time spent in level 1 hypoglycemia and level 1 hyperglycemia. However, serum PI showed no correlations with glycemic parameters in both groups (Fig. 3).

\section{Discussion}

Recent developments in continuous and intermittently scanned continuous glucose monitoring systems provide not only more efficient regulation of type 1 diabetes treatment, but also new information on glycemic parameters from the time of diagnosis. In this study, by using intermittently scanned glucose monitoring systems, the glycemic parameters of children with type 1 diabetes who are in RP and those who are not in RP were compared. As expected, the glycemic parameters in the RP were found to be closer to the target levels but were far from those of non-diabetic subjects [10]. It was found that while CP levels did have an effect on glycemic parameters during the PRP, there was no correlation between PI levels and glycemic parameters. In terms of glycemic parameters during the PRP, the CP level had a significant correlation with the TIR value.

New parameters are needed to define the PRP or preserved beta-cell reserve period. Although several studies [11-13] focused on the PRP and investigated PRPrelated factors, data related to the glycemic parameters during the PRP are limited. Meng et al. examined the relationship between blood glucose fluctuations during various phases of diabetes and oxidative stress and showed that the mean glucose, glucose $\mathrm{SD}$, the mean amplitude of glycemic excursions (MAGE) and incremental area under the blood glucose curve (IAUC) levels during the PRP were lower than those during the acute metabolic disturbance and long-standing phases [14]. Similarly, in our study, the mean sensor glucose level, $\mathrm{SD}$ value, $\mathrm{CV}$ value, time-in-range, time in hyperglycemia were found to be lower in the PRP group, suggesting a better metabolic control (Table 2). While the mean $\mathrm{CV}$ of $32.3 \%$ was lower than the target value of $36 \%$ in the CGMS consensus, [6] the mean SD value was higher than that found in a recent study analyzing the CGMS data of healthy children [9]. In addition, time spent in level 1 hypoglycemia was found to be similar in the PRP vs. non-PRP groups, indicating that glycemic control in PRP is restricted.

$\mathrm{CP}$ is a useful and widely used method of assessing pancreatic beta-cell function. The formula for IDAA1c was derived using a higher CP cut-off value of $300 \mathrm{pmol} /$ L. Therefore, although it previously played a role in defining the PRP, [3], it is no longer used to define the PRP. Venous blood CP levels can be measured in the random, fasting, or stimulated state. Random samples

Table 1. The demographic characteristics and laboratory findings of the participants

\begin{tabular}{llll}
\hline & PRP group (n:21) & Non-PRP group (n:31) & P value \\
\hline Age (year) & $9.3 \pm 3(5-13.7)$ & $8.9 \pm 2.6(5-13.8)$ & 0.67 \\
Gender (female/male) & $9 / 12$ & $16 / 15$ & 0.259 \\
Diabetes duration (years) & $0.57 \pm 0.5(0.04-1.7)$ & $4.3 \pm 1.5(2.2-8.7)$ & $<\mathbf{0 . 0 0 1}$ \\
Daily insulin dose (u/kg) & $0.35 \pm 0.11(0.13-0.5)$ & $0.81 \pm 0.16(0.55-1.25)$ & $<\mathbf{0 . 0 0 1}$ \\
HbA1c (\%) (mmol/mol) & $6.4(46) \pm 0.6(-17)((5.2(33)-7.6(60))$ & $7.2(55) \pm 0.6(-17)((6.2(44)-8.3(67))$ & $<0.001$ \\
IDDAA1C (\%)(mmol/mol) & $7.8(62) \pm 0.7(0.16)((6.8(51)-8.9(74))$ & $10.3(89) \pm 0.8(-0.15)((8.6(70)-11.9(107))$ & $<\mathbf{0 . 0 0 1}$ \\
Estimated HbA1c (\%) & $6.5 \pm 0.8(4.6-8.1)$ & $7.6 \pm 0.9(6.1-9.7)$ & $\mathbf{0 . 0 0 6}$ \\
CP level (pmol/L) (n:17) & $739.8 \pm 537.8(288-2582)$ & $465.6 \pm 478.9(102.6-1854)$ & $\mathbf{0 . 0 0 2}$ \\
PI level (pmol/L)(n:17) & $3.9 \pm 3.7(0.64-12.1)$ & $0.48 \pm 0.33(0.04-1.3)$ & $<\mathbf{0 . 0 0 1}$ \\
Pl:CP ratio & 0.55 & 0.13 & $<\mathbf{0 . 0 0 1}$ \\
\end{tabular}

IDDAA1C: Insulin Dose Adjusted HbA1C, CP C-peptide, PI Proinsulin, PI:CP Proinsulin to C-peptide ratio 
Table $\mathbf{2}$ Glycemic parameters of the participants

\begin{tabular}{|c|c|c|c|}
\hline & PRP group (n:21) & Non-PRP group (n:31) & $P$ value \\
\hline Sensor glucose overall (mean) $(\mathrm{mmol} / \mathrm{L})$ & $7.6 \pm 1.2(4.3-10.2)$ & $9.4 \pm 1.3(7.2-12.8)$ & $<0.001$ \\
\hline Sensor glucose (mean) Day-time (06-00) (mmol/L) & $7.6 \pm 1.2(1.2-10)$ & $9.4 \pm 1.3(7.3-12.8)$ & 0.001 \\
\hline Sensor glucose (mean) Night-time(00-06)(mmol/L) & $7.5 \pm 1.6(4.2-11)$ & $9.4 \pm 1.9(6.2-13.7)$ & 0.002 \\
\hline CV overall (mean) \% & $32.3 \pm 5(21-44)$ & $40.5 \pm 6(32-56)$ & $<0.001$ \\
\hline CV day-time (mean) \% & $32.1 \pm 4.7(21-42)$ & $40.6 \pm 6(33-54)$ & $<0.001$ \\
\hline CV night-time(mean) \% & $29 \pm 5(19-45)$ & $38.2 \pm 1(24-64)$ & $<0.001$ \\
\hline $\mathrm{SD}$ overall (mean)(mmol/L) & $2.5 \pm 0.6(1-3.7)$ & $3.8 \pm 0.7(2.7-5.2)$ & $<0.001$ \\
\hline SD day-time (mean)(mmol/L) & $2.5 \pm 0.7(1-3.6)$ & $3.8 \pm 0.6(2.6-5.1)$ & $<0.001$ \\
\hline SD night-time (mean) (mmol/L) & $2.2 \pm 0.7(0.9-4.1)$ & $3.5 \pm 1(2.2-6)$ & $<0.001$ \\
\hline $\begin{array}{l}\text { Overall time-in-range } \\
(3.9-10 \mathrm{mmol} / \mathrm{L}(\%)\end{array}$ & $76.2 \pm 11.6(46.9-96.2)$ & $50 \pm 17.4(9-78.8)$ & $<0.001$ \\
\hline Time-in-range (daytime)(\%) & $76 \pm 11.5(48.8-97.4)$ & $50.1 \pm 17.4(9.6-79.9)$ & $<0.001$ \\
\hline Time-in-range (night-time) (\%) & $75.9 \pm 16.7(38.9-93)$ & $48.8 \pm 20(6.5-77.7)$ & $<0.001$ \\
\hline Time in level 1 hypoglycemia(<3.9mmol/L) overall (\%) (median) & $2(0.2-28.6)$ & $5.2(0.1-19.5)$ & 0.056 \\
\hline Time in level 1 hypoglycemia(<3.9mmol/L) day-time (\%) (median) & $1.7(0-44)$ & $4.4(0.15-18.5)$ & 0.039 \\
\hline Time in level 1 hypoglycemia(<3.9mmol/L) night-time (\%) (median) & $1.8(0-44)$ & $4.1(0-31)$ & 0.185 \\
\hline Time in level 1 hyperglycemia(>10mmol/L) overall (\%) (median) & 19.8(0-50) & $37.1(4-73)$ & $<0.001$ \\
\hline Time in level 1 hyperglycemia(>10 mmol/L) day-time (\%) (median) & $22.4(0-49)$ & $38.6(4.2-71.6)$ & $<0.001$ \\
\hline Time in level 1 hyperglycemia(>10 mmol/L) night-time (\%) (median) & $13.3(0-60)$ & $36.7(1.6-77.4)$ & 0.001 \\
\hline
\end{tabular}

CV Coefficient of variation, SD Standard Deviation

are taken at any time during the day without consideration of recent food intake, whereas fasting samples are taken after an 8 to $10 \mathrm{~h}$ fast [8]. In the present study, serum $\mathrm{CP}$ levels were measured in the random state, and as expected the mean $\mathrm{CP}$ level was significantly higher in the PRP group than in the non-PRP group. Although $\mathrm{CP}$ is a widely accepted biochemical parameter for pancreatic beta-cell reserve, data on the association between $\mathrm{CP}$ levels and glycemic parameters are very limited. In the present study, the presence of a correlation between
$\mathrm{CP}$ levels and glycemic parameters was evaluated. In the PRP group, the mean CP level was inversely correlated with the mean sensor glucose and SD glucose whereas it positively correlated with TIR. These findings support that $\mathrm{CP}$ might be a relevant biochemical parameter in the PRP. However, the presence of a positive correlation between $\mathrm{CP}$ and time in both level 1 hypoglycemia and level 1 hyperglycemia in the non-PRP group suggests that $\mathrm{CP}$ is not a reliable parameter when it is low. On the other hand, release of islet hormones is regulated

Table 3 Correlations between PI, CP, PI:CP ratio and glycemic parameters

\begin{tabular}{|c|c|c|c|c|c|c|c|c|}
\hline & & $\begin{array}{l}\text { Time-in-range } \\
\text { Overall }\end{array}$ & $\begin{array}{l}\text { Time in } \\
\text { Level } 1 \\
\text { Hypoglycemia } \\
\text { Overall }\end{array}$ & $\begin{array}{l}\text { Time in } \\
\text { Level } 1 \\
\text { Hyperglycemia } \\
\text { Overall }\end{array}$ & $\begin{array}{l}\text { Mean } \\
\text { HbA1C }\end{array}$ & $\begin{array}{l}\text { Mean Sensor } \\
\text { Glucose Overall }\end{array}$ & $\begin{array}{l}\text { Mean SD } \\
\text { Overall }\end{array}$ & $\begin{array}{l}\text { Mean CV } \\
\text { Overall }\end{array}$ \\
\hline \multirow[t]{2}{*}{$\begin{array}{l}\mathrm{C} \text { - } \\
\text { peptide }\end{array}$} & PRP & $r_{1}: 0.65 P_{1}: 0.03$ & $r_{1}:=0.009 P_{1}: 0.97$ & $r_{1}:=0.56 P_{1}: 0.015$ & $\begin{array}{l}r_{1}: 0.27 P_{1}: \\
0.26\end{array}$ & $r_{1}:-0.47 P_{1}: 0.048$ & $r_{1}:-0.62 P_{1}: 0.006$ & $\begin{array}{l}R_{1}:-0.29 P_{1}: \\
0.23\end{array}$ \\
\hline & $\begin{array}{l}\text { Non- } \\
\text { PRP }\end{array}$ & $r_{2}: 0.09 P_{2: 0.7}$ & $r_{2:} 0.61 P_{2: 0} 0.009$ & $P_{2: 0.041}{ }^{r_{2}: 0.5}$ & $\begin{array}{l}r_{2:}: 0.06 \\
P_{2: 0.98}\end{array}$ & $r_{2:-0.01} P_{2: 0.95}$ & $r_{2: 0.191} P_{2: 0.462}$ & $\begin{array}{l}\mathrm{R}_{2}: 0.37 \\
\mathrm{P}_{2: 0.14}\end{array}$ \\
\hline \multirow[t]{2}{*}{ Proinsulin } & PRP & $r_{1}: 0.23 P_{1}: 0.34$ & $r_{1}:=0.29 P_{1}: 0.24$ & $\begin{array}{l}r_{1}:=0.16 \\
P_{1}: 0.52\end{array}$ & $\begin{array}{l}r_{1}: 0.16 P_{1}: \\
0.50\end{array}$ & $r_{1}:=0.05 P_{1}: 0.84$ & $r_{1}:=0.24 P_{1}: 0.32$ & $\begin{array}{l}R_{1}:=0.41 P_{1}: \\
0.08\end{array}$ \\
\hline & $\begin{array}{l}\text { Non- } \\
\text { PRP }\end{array}$ & $r_{2:}-0.94 P_{2:} 0.45$ & $r_{2: 0.07} P_{2}: 0.765$ & $\begin{array}{l}r_{2}: 0.24 \\
P_{2: 0.348}\end{array}$ & $\begin{array}{l}r_{2}: 0.16 \\
P_{2: 0.53}\end{array}$ & $r_{2: 0.16} P_{2: 0.52}$ & $r_{2: 0.22} P_{2: 0.39}$ & $\begin{array}{l}\mathrm{R}_{2}: 0.02 \\
\mathrm{P}_{2: 0.94}\end{array}$ \\
\hline \multirow[t]{2}{*}{$\begin{array}{l}\mathrm{Pl} / \mathrm{CP} \\
\text { ratio }\end{array}$} & PRP & $r_{1}: 0.06 P_{1}: 0.78$ & $r_{1}:=0.38 P_{1}: 0.11$ & $\begin{array}{l}r_{1}: 0.01 \\
P_{1}: 0.95\end{array}$ & $\begin{array}{l}r_{1}: 0.15 P_{1}: \\
0.54\end{array}$ & $r_{1}: 0.09 P_{1}: 0.69$ & $r_{1}:-0.06 P_{1}: 0.79$ & $\begin{array}{l}R_{1}:=0.42 P_{1}: \\
0.07\end{array}$ \\
\hline & $\begin{array}{l}\text { Non- } \\
\text { PRP }\end{array}$ & $r_{2:}-0.35 P_{2: 0.62}$ & $r_{2:}=0.55 P_{2:} 0.02$ & $\begin{array}{l}r_{2}: 0.09 \\
P_{2}: 0.71\end{array}$ & $\begin{array}{l}r_{2}: 0.28 \\
P_{2}: 0.27\end{array}$ & $r_{2: 0.37} P_{2: 0.13}$ & $r_{2: 0.18} P_{2: 0.48}$ & $\begin{array}{l}\mathrm{R}_{2:}: 0.41 \\
\mathrm{P}_{2: 0.09}\end{array}$ \\
\hline
\end{tabular}

CV Coefficient of variation, SD Standard Deviation, PI:CP Proinsulin to C-peptide ratio 


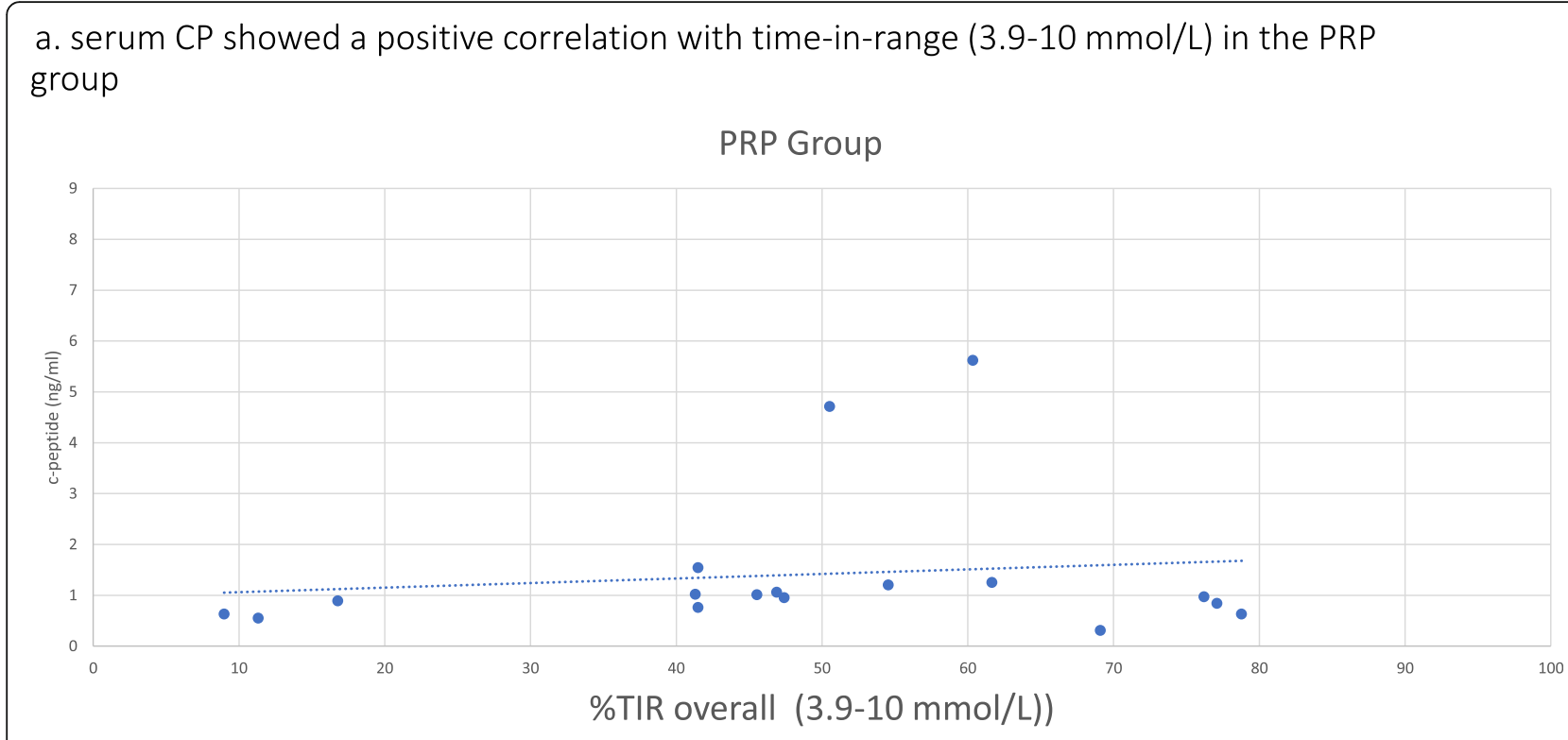

\section{b. Serum CP showed no correlation with time-in-range $(3.9-10 \mathrm{mmol} / \mathrm{L})$ in the non- PRP group}

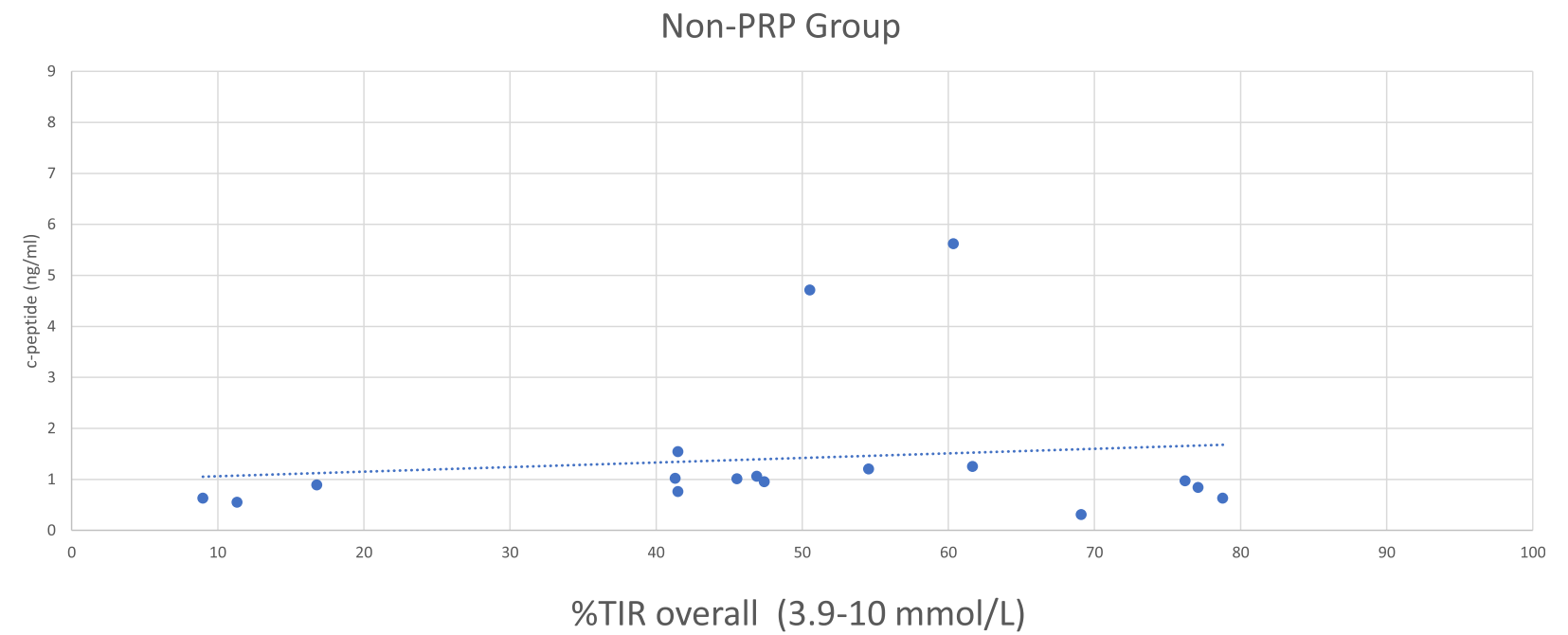

Fig. 2 Correlation between C-peptide and TIR in PRP and non-PRP groups. a Serum CP showed a positive correlation with time-in-range (3. 9-10 $\mathrm{mmol} / \mathrm{L})$ in the PRP group. $\mathbf{b}$ Serum CP showed no correlation with time-in-range $(3.9-10 \mathrm{mmol} / \mathrm{L})$ in the non-PRP group

not only by direct actions of glucose and other nutrients, but also indirectly and potently by paracrine factors secreted by adjacent islet cells. The current knowledge shows that islet cells modulate each other's secretory functions by very complex paracrine and even autocrine pathways. Low beta cell reserve, low CP may be associated with increased hypoglycaemia, possibly via secondary effects on the beta-cell alpha-cell cross talk and lower glucagon secretion $[15,16]$.

Recent studies reported an increased risk of developing 5-year T1D in antibody-positive first-degree relatives having an increased PI / CP ratio [17]. Similarly, the PI/ $\mathrm{CP}$ ratio was found to be higher at the time of diagnosis of diabetes compared with the control group [18]. Although PI is used as a beta-cell stress marker, two recent studies showed that PI secretion was maintained for a long time and that the level of CP was still detectable many years after diagnosis in individuals with T1D [19, 20]. In our study, both the PI level and PI / CP ratio were significantly higher in the PRP group. In the nonPRP group, however, two children who were aged 6.2 and 12-year-old and whose diabetes duration was 2.3 


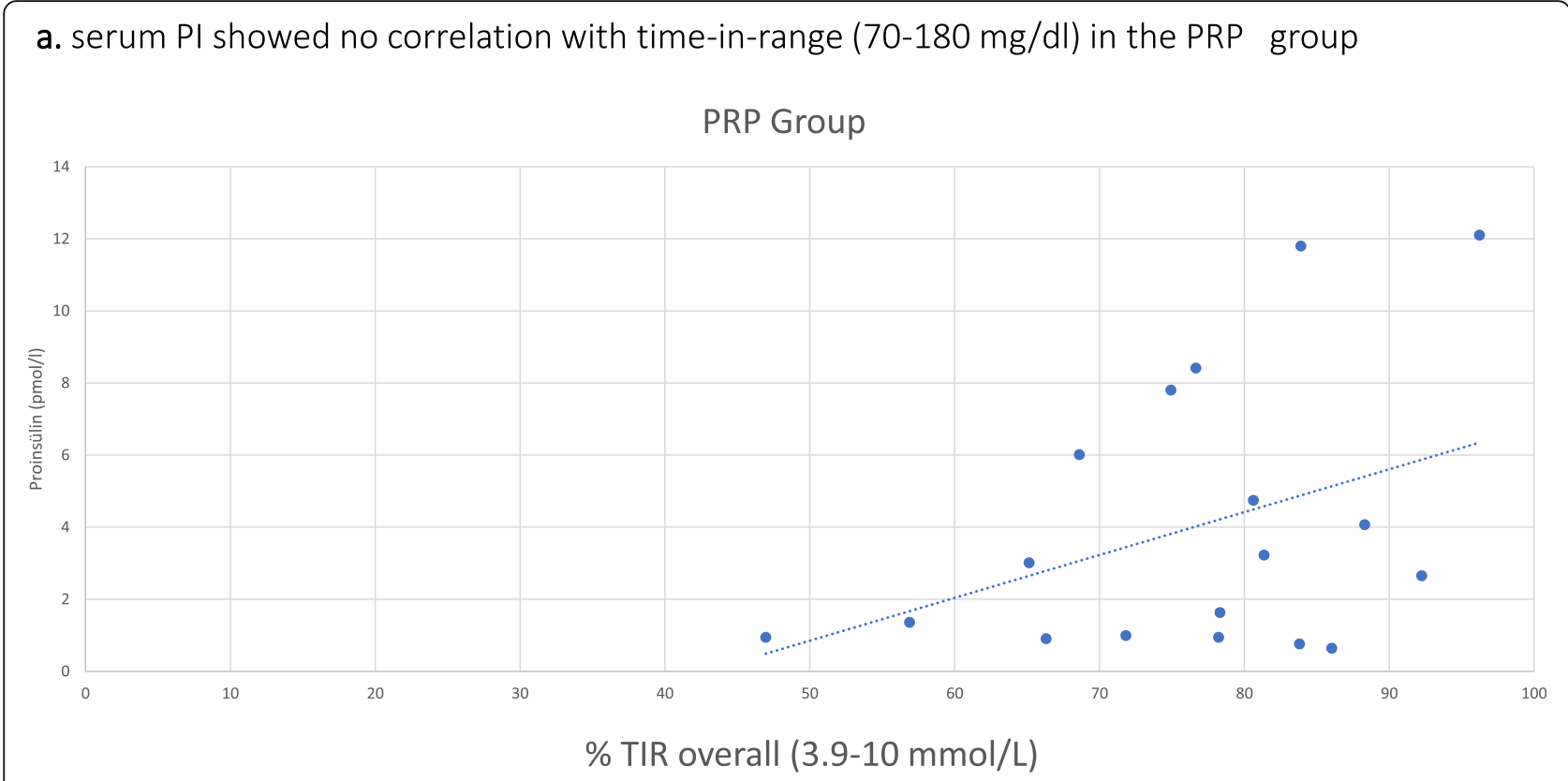

b. serum PI showed no correlation with time-in-range (70-180 mg/dl) in the non-PRP group

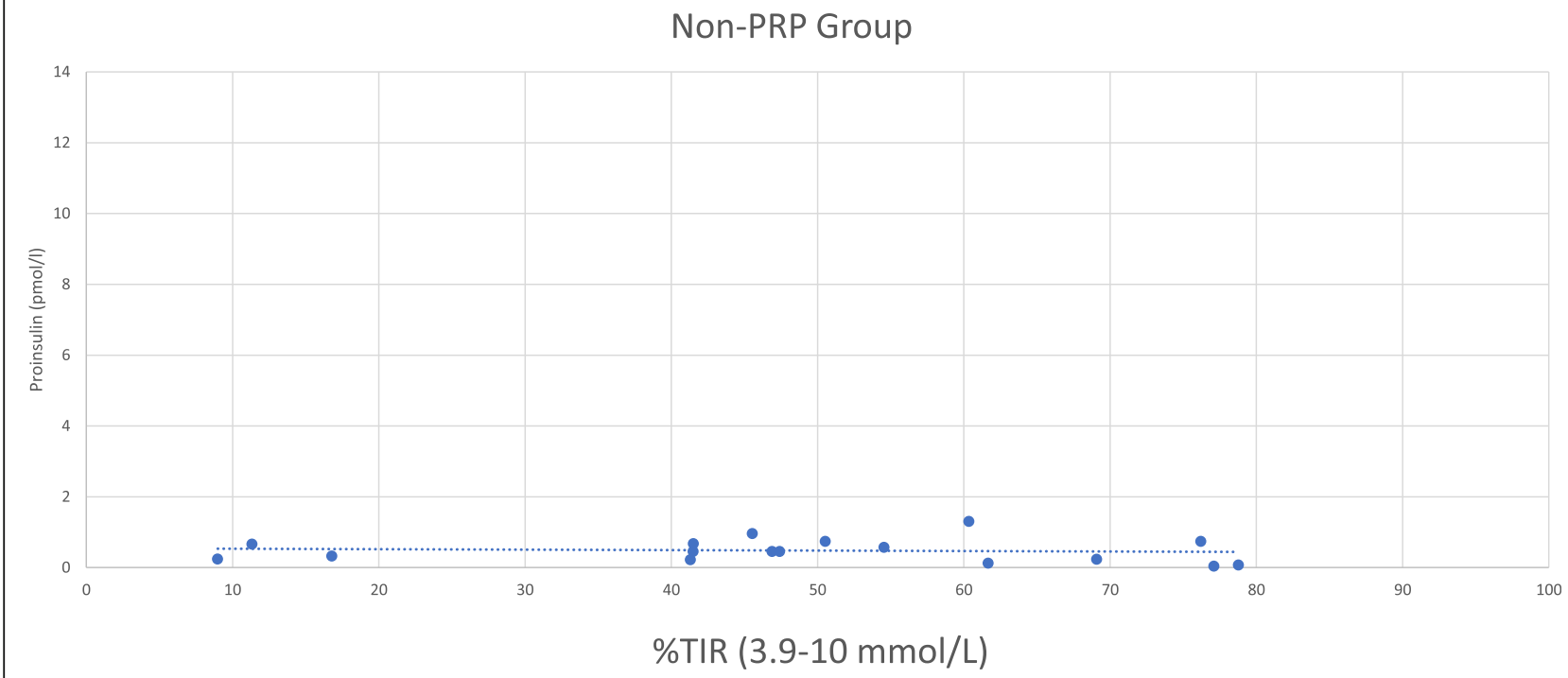

Fig. 3 Correlation between Proinsulin and TIR in PRP and non-PRP groups. a Serum PI showed no correlation with time-in-range (3.9-10 mmol/L) in the PRP group. $\mathbf{b}$ Serum PI showed no correlation with time-in-range $(3.9-10 \mathrm{mmol} / \mathrm{L})$ in the non-PRP group

and 8.7 years had $\mathrm{CP}$ levels below the measurable limit despite detectable PI levels. Due to the small size of the patient groups, it is difficult to comment on the differences in the maintenance of CP and PI secretions. In this study, no significant correlation was detected between proinsulin levels and glycemic parameters in any group, suggesting that proinsulin is not as clinically reliable as $\mathrm{CP}$ in the management of diabetes. Although its level in the PRP is higher than the non-PRP group, proinsulin shows beta cell stress and rather provides information about the earlier phase of diabetes [4] The PRP is a relatively later period of the beta cell injury process. Therefore, there may not be a relationship between glycemic parameters and proinsulin levels in this phase.

One of the main limitations of our study was the random measurement of $\mathrm{CP}$ and PI levels. These measures may have been affected by the degree of fasting, which was not taken into account because we recruited 
patients during scheduled outpatient follow-up visits. Measurements of stimulated CP and PI secretions using tests such as a mixed-meal tolerance test may be beneficial, as well. However, this study design would require more inconvenience to the participants and their families. Moreover, Watkins et al. conducted a research by random sampling for the $\mathrm{CP}$ and PI measurement in order to evaluate the $\beta$-cell function in persons with T1D [5] and Leighton et al. in their review article had stated that venous blood CP levels can be measured in the random, fasting, or stimulated state [8]. Another limitation was the lack of simultaneous blood glucose measurements with the use of isCGMS which does not require calibration. The accuracy of isCGMS was reported to be lower during hypoglycemia than during euglycemia and hyperglycemia [21]. However, time spent in level 1 hypoglycemia was not high and similar in both groups. Despite these limitations, we feel that this pilot study is important as it is the first study to evaluate glycemic parameters in the PRP with the use of isCGMS data and to examine the relationship between these parameters and Beta-cell reserve markers $\mathrm{CP}$ and PI. There is no doubt that a future study with larger patient numbers would show more generalizable results.

\section{Conclusions}

In conclusion, although the glycemic profile during the PRP was better than that in the non-PRP group, the glycemic variability during this period was not as low as expected. It is also important to continue efforts to improve and maintain metabolic control during the PRP. Subcutaneous insulin infusion or automated insulin delivery systems may help to achieve better glycemic control in the remission phase as well. While the $\mathrm{CP}$ levels showed an association with TIR during the PRP, there was no correlation between PI levels and glycemic parameters. Further studies are needed to determine if PI might prove to be a useful parameter in clinical follow-up.

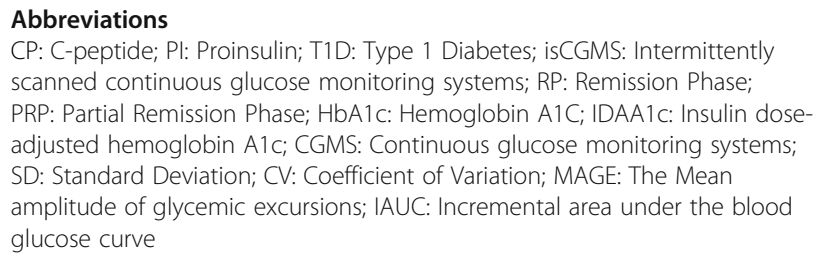

\section{Acknowledgements}

The authors would like to thank all the children with type 1 diabetes and their parents who participated in our study and Alan J. Newson for English language editing.

\section{Authors' contributions}

GYM, MC, EC, TG, GB, SM, SI, EPC, SH contributed to the study concept and design. GYM and ŞH supervised the study. GYM, MÇ, EC and GB collected data. All authors participated in data analysis and interpretation. The manuscript was drafted by GYM and MÇ, reviewed by GYM, MÇ, EC, TG, GB,
SM, SI, EPÇ, ŞH and edited by GYM and ŞH. All contributing authors approved the final version of the manuscript.

Funding

This research did not receive any specific grant.

\section{Availability of data and materials}

The datasets used and/or analysed during the current study are available from the corresponding author on reasonable request.

\section{Ethics approval and consent to participate}

All procedures performed in studies involving human participants were in accordance with the ethical standards of the institutional and/or national research committee and with the 1964 Helsinki Declaration and its later amendments or comparable ethical standards. The study protocol was approved (approval number:2018.022.IRB1.004) by the Koç University Committee on Human Research (reference number:2018.022.IRB1.004). Written informed consent was obtained from the parents along with assent from the adolescents as required by the local institutional review board regulations. Written informed consent was obtained from the parents/ guardians of the minors included in this study (minors are considered anyone under the age of 16).

\section{Consent for publication}

Not applicable.

\section{Competing interests}

The authors declare that they have no competing interest.

\section{Author details}

'Department of Pediatric Endocrinology and Diabetes, Koç University Hospital, Topkapı, Zeytinburnu, 34010 Istanbul, Turkey. ${ }^{2}$ Koç University School of Medicine, Istanbul, Turkey. ${ }^{3}$ Department of Biochemistry, Koç University Hospital, Istanbul, Turkey. ${ }^{4}$ Department of Pediatric Endocrinology, Bakirköy Dr Sadi Konuk Training and Research Hospital, Istanbul, Turkey.

Received: 13 September 2020 Accepted: 13 January 2021

Published online: 23 January 2021

\section{References}

1. Chetan MR, Charlton MH, Thompson C, Dias RP, Andrews RC, Narendran P. The type 1 diabetes 'honeymoon'period is five times longer in men who exercise: a case-control study. Diabet Med. 2019;36(1):127-8.

2. Wallensteen M, Dahlquist G, Persson B, Landin-Olsson M, Lernmark $\AA$, Sundkvist G, Thalme B. Factors influencing the magnitude, duration, and rate of fall of B-cell function in type 1 (insulin-dependent) diabetic children followed for two years from their clinical diagnosis. Diabetologia. 1988;31(9): 664-9.

3. Mortensen HB, Hougaard P, Swift P, Hansen L, Holl RW, Hoey H, Bjoerndalen H, De Beaufort C, Chiarelli F, Danne T, Schoenle EJ. New definition for the partial remission period in children and adolescents with type 1 diabetes. Diabetes Care. 2009;32(8):1384-90.

4. Sullivan CA, Cacicedo JM, Rajendran I, Steenkamp DW. Comparison of proinsulin and C-peptide secretion in healthy versus long-standing type 1 diabetes mellitus cohorts: a pilot study. PLoS One. 2018;13(11):e0207065.

5. Watkins RA, Evans-Molina C, Terrell JK, Day KH, Guindon L, Restrepo IA, Mirmira RG, Blum JS, DiMeglio LA. Proinsulin and heat shock protein 90 as biomarkers of beta-cell stress in the early period after onset of type 1 diabetes. Transl Res. 2016:168:96-106.

6. Danne T, Nimri R, Battelino T, Bergenstal RM, Close KL, DeVries JH, Garg S, Heinemann L, Hirsch I, Amiel SA, Beck R. International consensus on use of continuous glucose monitoring. Diabetes Care. 2017;40(12):1631-40.

7. Dhahir FJ, Cook DB, Self CH. Amplified enzyme-linked immunoassay of human proinsulin in serum (detection limit: 0.1 pmol/L). Clin Chem. 1992; 38(2):227-32.

8. Leighton E, Sainsbury CA, Jones GC. A practical review of C-peptide testing in diabetes. Diabetes therapy. 2017:8(3):475-87.

9. Dean AG, Sullivan KM, Soe MM. OpenEpi: Open Source Epidemiologic Statistics for Public Health, Version. www.OpenEpi.com, updated 2013/04/06.

10. Derosa G, Salvadeo SA, Mereu R, D'Angelo A, Ciccarelli L, Piccinni MN, Ferrari I, Gravina A, Maffioli P, Tinelli C. Continuous glucose monitoring 
system in free-living healthy subjects: results from a pilot study. Diabetes Technol Ther. 2009;11(3):159-69.

11. Chiavaroli V, Derraik JG, Jalaludin MY, Albert BB, Ramkumar S, Cutfield WS, Hofman PL, Jefferies CA. Partial remission in type 1 diabetes and associated factors: analysis based on the insulin dose-adjusted hemoglobin A1c in children and adolescents from a regional diabetes center, Auckland. New Zealand Pediatric diabetes. 2019;20(7):892.

12. Cengiz E, Cheng P, Ruedy K, Kollman C, Tamborlane WW, et al. Clinical outcomes in youth beyond the first year of type 1 diabetes: results of the pediatric diabetes consortium (PDC) type 1 diabetes new onset (NeOn) study. Pediatr Diabetes. 2017;18(7):566-73.

13. Böber E, Dündar B, Büyükgebiz A. Partial remission phase and metabolic control in type 1 diabetes mellitus in children and adolescents. J Pediatr Endocrinol Metab. 2001;14(4):435-41.

14. Meng X, Gong C, Cao B, Peng X, Wu D, Gu Y, Wei L, Liang X, Liu M, Li W, Su C. Glucose fluctuations in association with oxidative stress among children with T1DM: comparison of different phases. J Clin Endocrinol Metabol. 2015; 100(5):1828-36.

15. Gaisano HY, Macdonald PE, Vranic M. Glucagon secretion and signaling in the development of diabetes. Front Physiol. 2012;3:349. https://doi.org/10. 3389/fphys.2012.00349 PMID: 22969729; PMCID: PMC3432929.

16. Christensen MB, Gæde P, Hommel E, Gotfredsen A, Nørgaard K. Glycaemic variability and hypoglycaemia are associated with C-peptide levels in insulin-treated type 2 diabetes. Diabetes Metab. 2020;46(1):61-5. https://doi. org/10.1016/j.diabet.2019.02.002 Epub 2019 Feb 21. PMID: 30796973.

17. Truyen I, De Pauw P, Jørgensen PN, Van Schravendijk C, Ubani O, Decochez K, Vandemeulebroucke E, Weets I, Mao R, Pipeleers DG, Gorus FK. Proinsulin levels and the proinsulin: c-peptide ratio complement autoantibody measurement for predicting type 1 diabetes. Diabetologia. 2005;48(11): 2322-9.

18. Schölin A, Nyström L, Arnqvist H, Bolinder J, Björk E, Berne C, Karlsson FA. Diabetes incidence study Group in Sweden (DISS). Proinsulin/C-peptide ratio, glucagon and remission in new-onset type 1 diabetes mellitus in young adults. Diabet Med. 2011;28(2):156-61.

19. Sims EK, Bahnson HT, Nyalwidhe J, Haataja L, Davis AK, Speake C, DiMeglio LA, Blum J, Morris MA, Mirmira RG, Nadler J. Proinsulin secretion is a persistent feature of type 1 diabetes. Diabetes Care. 2019:42(2):258-64.

20. Steenkamp DW, Cacicedo JM, Sahin-Efe A, Sullivan C, Sternthal E. Preserved proinsulin secretion in long-standing type 1 diabetes. Endocr Pract. 2017; 23(12):1387-93.

21. Leelarathna L, Wilmot EG. Flash forward: a review of flash glucose monitoring. Diabet Med. 2018;35(4):472-82.

\section{Publisher's Note}

Springer Nature remains neutral with regard to jurisdictional claims in published maps and institutional affiliations.

Ready to submit your research? Choose BMC and benefit from:

- fast, convenient online submission

- thorough peer review by experienced researchers in your field

- rapid publication on acceptance

- support for research data, including large and complex data types

- gold Open Access which fosters wider collaboration and increased citations

- maximum visibility for your research: over $100 \mathrm{M}$ website views per year

At $\mathrm{BMC}$, research is always in progress.

Learn more biomedcentral.com/submissions 